УДК629.424.1.06

\title{
МОДЕРНИЗАЦИЯ ОХЛАЖДАЮЩИХ УСТРОЙСТВ ТЕПЛОВОЗА
}

Канд. техн. наук О.В. Пасько, В.В. Белохонов

МОДЕРНІЗАЦІ ОХОЛОДЖУЮЧИХ ПРИСТРОЇВ ТЕПЛОВОЗУ

Канд. техн. наук О.В. Пасько, В.В. Бєлохонов

\section{MODERNIZATION OF COOLING DEVICES LOCOMOTIVE}

\author{
Cand. of tehn. sciences O.V. Pasko, V.V. Belohonov
}

В данной статье рассматривается возможность применения экспериментальных секиий радиаторов из алюминиевого сплава систем охлаждения тепловозов. В ходе процесса оптимизачии охлаждающих устройств тепловозов проведен сравнительный расчет целевой функции для различных климатических условий эксплуатации. Стоимость жизненного циикла охлаждающего устройства тепловоза при проектировании значительно зависит от режима работы тепловоза. Это обстоятельство обусловлено меньшими затратами мощности на привод вентилятора холодильной камеры и как следствие сниюением потребления топлива на вспомогательные нужды.

Ключевые слова: охлаждающчие устройства тепловозов, секции радиатора плоскоовальные, каплеобразные.

У даній статті розглядається можсливість застосування експериментальних секиій радіаторів з алюмінієвого сплаву систем охолодження тепловозів.B ході прочесу оптимізації пристроїв тепловозів, щзо охолоджують, проведений порівняльний розрахунок ичільової функиії для різних кліматичних умов експлуатаиії. Вартість життєвого ичиклу пристрою тепловоза, щзо охолоджує, при проектуванні значно залежить від режиму роботи тепловоза. Ця обставина обумовлена меншими витратами потужності на привід вентилятора холодильної камери і як наслідок зниженням вжитку палива на допоміжні витрати.

Ключові слова: охолоджуючі пристрої тепловозів, секції радіатора, плоскоовальні, каплеподібні.

This article discusses the possibility of applying the experimental sections of aluminum alloy radiator cooling systems of diesel locomotives. During process of optimization of cooling devices of locomotives comparative calculation of criterion function for various climatic conditions of operation is carried out. The cost of life cycle of the cooling device of a locomotive at design considerably depends on a locomotive operating mode. This circumstance is caused by smaller costs of power of the drive of the fan of the refrigerator and as a result decrease in consumption of fuel of auxiliary needs.

Keywords: cooling devices locomotives, radiator sections flat-oval, drop-shaped.

Разработчики и создатели отечественных тепловозов традиционно придерживаются универсальных принципов создания охлаждающих устройств тепловозов, ориентируясь на температуры окружающей среды от +40 до $-45^{\circ} \mathrm{C}$.

В 96\% случаев браки в работе охлаждающих устройств тепловозов 
вызваны появлением течи в секциях радиаторов тепловоза.

На сегодняшний день явно обозначилась необходимость поиска и реализации инновационных средств и методов повышения эффективности охлаждающих устройств тепловозов.

Одним из направлений повышения эффективности охлаждающих устройств тепловоза стало использование алюминиевых сплавов для изготовления радиаторов, что позволяло бы полностью отказаться от применения более дорогостоящей меди.

Согласно законам термодинамики интенсивность теплопередачи трубчатопластинчатых охлаждений устройств во многом зависит от толщины пограничного теплоносителя, и особенно воздуха. Низкая теплопроводность пограничного слоя воздуха существенно ограничивает теплоотдачу к нему с поверхности стенок теплообменника. Известные способы интенсификации процесса теплоотдачи (изменение угла атаки воздушного потока, смачивание поверхностей охлаждения, перфорация пластин оребрения и др.) определяют единую цель - уменьшение толщины ламинарного температурного пограничного слоя у поверхности охлаждения.

Таким образом, турбулизация потока воздуха, а следовательно и форма омываемой поверхности охлаждения играют ключевую роль.

В фундаментальных исследованиях процессов теплоотдачи тел различной формы к воздуху установлено, что форма поверхности в виде плоского овала и каплеобразная способны обеспечивать большую интенсивность теплоотдачи по сравнению с известными круглыми, эллипсовидными и многими другими формами трубок.

Методом имитационного моделирования разработана конструкция водовоздушной секции радиатора с оптимальными

геометрическими параметрами. На рис. 1 представлен фрагмент внешнего вида (в разрезе), модели опытной секции радиатора с каплеобразными формами сечения трубок.

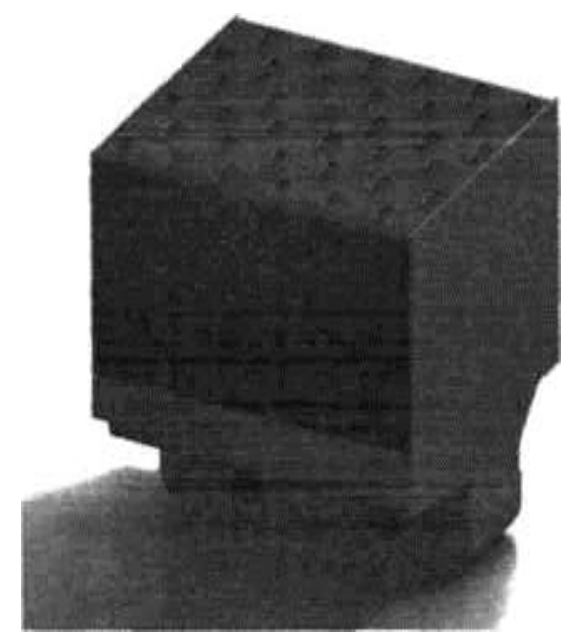

Рис. 1. Фрагмент секции радиатора охлаждающих устройств тепловоза

Проектирование опытной секции радиатора выполнено с максимальным приближением к унифицированной секции по следующим элементам: коллекторные коробки, усилительная доска, пластины оребрения. Сравнительные технические характеристики секций с плоскоовальными и каплеобразными трубками приведены в таблице.

Как видно из таблицы, масса разработанной секции радиатора снизилась на 8 кг, в том числе масса цветных металлов - на 6 кг. В итоге площадь поверхности охлаждения и вес цветных металлов снижены на $20 \%$ по сравнению со стандартной. Обоснованное оптимальное сечение каплеобразной трубки принято равным $50 \mathrm{MM}^{2}$. В результате гидравлическое сопротивление секции уменьшено на $50 \%$, аэродинамическое сопротивление снижено на $3 \%$. 
Характеристики стандартной и предлагаемой секций радиаторов

Таблица

\begin{tabular}{|c|c|c|}
\hline Наименование & $\begin{array}{c}\text { Стандартная секция } \\
\text { радиатора с } \\
\text { плоскоовальными } \\
\text { трубками (ВП-1,2) }\end{array}$ & $\begin{array}{c}\text { Секция радиатора } \\
\text { с каплеобразными } \\
\text { трубками }\end{array}$ \\
\hline $\begin{array}{l}\text { Расстояние между центрами отверстий } \\
\text { крепления, мм }\end{array}$ & 1356 & 1356 \\
\hline $\begin{array}{l}\text { Габариты секции радиатора, мм: } \\
\text { высота } \\
\text { ширина } \\
\text { глубина }\end{array}$ & $\begin{array}{l}1206 \\
154 \\
187\end{array}$ & $\begin{array}{c}1206 \\
154 \\
133 \\
\end{array}$ \\
\hline Форма трубки & плоскоовальная & каплеобразная \\
\hline Размеры трубок, мм & $19,5 \times 2,2$ & по чертежу \\
\hline Сечения трубки для воды, мм² & 21 & 50 \\
\hline Толщина стенки трубок, мм & 0,55 & 0,55 \\
\hline Расположение трубок & \multicolumn{2}{|c|}{ Шахматное } \\
\hline $\begin{array}{l}\text { Шаг расположения трубок, мм: } \\
\text { по фронту } \\
\text { по глубине }\end{array}$ & $\begin{array}{l}16 \\
22\end{array}$ & $\begin{array}{l}23 \\
22\end{array}$ \\
\hline Число рядов трубок по глубине & 8 & 6 \\
\hline Число трубок в секции, шт. & 68 & 36 \\
\hline $\begin{array}{l}\text { Пластины оребрения: } \\
\text { шаг, мм } \\
\text { толщина, мм, } \\
\text { число в секции }\end{array}$ & $\begin{array}{c}2,83 \\
0,1 \\
422 \times 2\end{array}$ & $\begin{array}{c}2,83 \\
0,1 \\
422 \times 2\end{array}$ \\
\hline Живое сечение для прохода воздуха, м2 & 0,1361 & 0,092 \\
\hline Живое сечение для прохода воды, м2 & 0,00132 & 0,0018 \\
\hline Поверхность теплообмена, м $^{2}$ & 21,0 & 17,0 \\
\hline Поверхность теплообмена, м² & 3,04 & 1,6 \\
\hline Вес цветных металлов в секции & 35,0 & 29,0 \\
\hline Вес секции, кг & 45,65 & 37,5 \\
\hline
\end{tabular}

Для предлагаемой модели секции радиаторов получены аналитические критериальные уравнения теплоотдачи и аэродинамики:

$$
\begin{aligned}
& N_{u \text { acp }}=2,09 \cdot R_{e}{ }^{0,252}, \\
& E_{u s c p}=0,14 \cdot R_{e}^{-0,073} .
\end{aligned}
$$

Сечение каплеобразной трубки принято равным $50 \mathrm{mм}^{2}$, при этом в качестве определяющего размера для уравнений (1)-(2) принят эквивалентный диаметр узкого сечения канала для прохода воздуха, который равняется 0,0049 м; определяющая температура - 293,2 К; $\mathrm{P}_{\Gamma}=0,72 ;$ уравнение справедливо для $500<\operatorname{Re}<4200$.

В расчете технико-экономической эффективности как целевой функции $C$ были использованы технические характеристики тепловоза ТЭ70 с дизелем 2Д-9ДГ-02: мощность - 3022 кВт; механический к.п.д. - 0,893; частота вращения вала дизеля на номинальной 
мощности - 1000 об/мин; частота вращения на расчетных режимах - 740 об/мин; коэффициент отвода тепла с водой системы охлаждения - 0,13; удельный расход масла дизелем - 0,0285 кг/кВт·ч.

Для расчета параметров холодильной камеры тепловоза приняты следующие значения: диаметр вентиляторного колеса $1,6 \mathrm{~m}$; ширина и высота отсеков для постановки радиатора - 1,694×1,206 м; площадь сечения, ометаемая лопастями, -

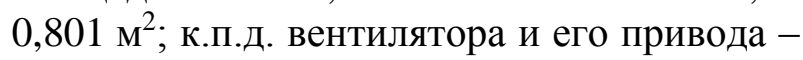
0,78 .

Принятыми техническими параметрами водяной системы охлаждения (первого контура) являются: производи- тельность водяного насоса $80 \mathrm{~m}^{3} / \mathrm{ч}$; падение давления в трубопроводе (согласно расчету) 0,03 кГ/ $\mathrm{cm}^{2}$; падение давления в дизеле тепловоза (согласно расчету) 0,15 кГ/ $\mathrm{cm}^{2} ;$ к.п.д водяного насоса 0,8 .

При расчете учитывались технические характеристики стандартных и предлагаемых секций радиаторов. Общими характеристиками являлись: расход теплоносителей (вода и воздух); ширина радиатора 154 мм; высота радиатора по осям $1350 \mathrm{мm;} \mathrm{расположение} \mathrm{секций} \mathrm{в}$ шахте холодильника - боковое; работа вентилятора на всасывание.

Результаты расчета целевой функции $C$ представлены на рис. 2.

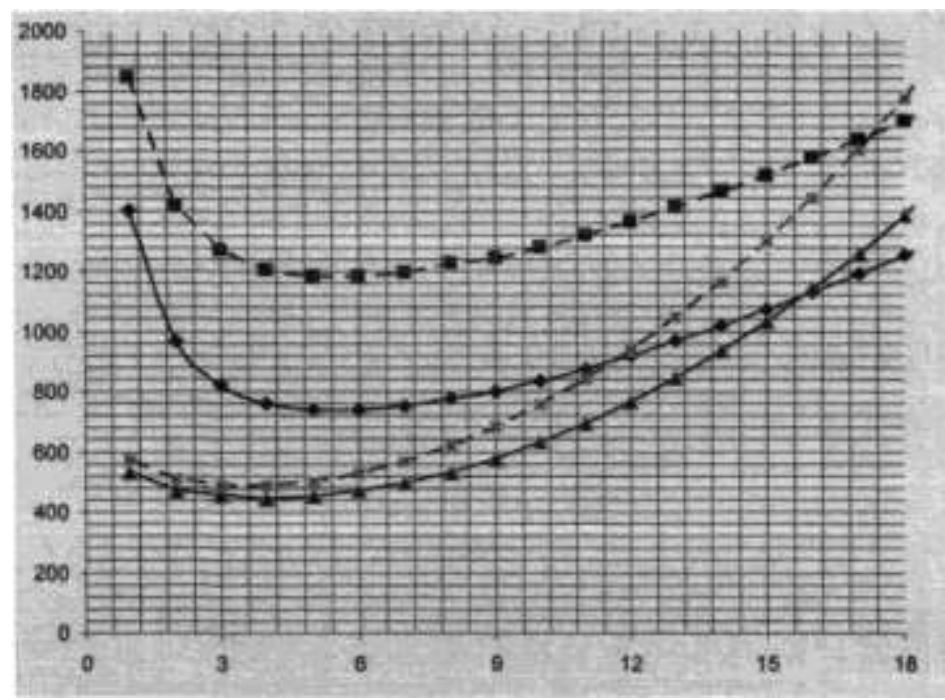

ппроект ОУТ со стандартными секциями радиаторов работа ОУТ с учетом надежности стандартных секций радиаторов

шпроект ОУТ с предлагаемыми секциями радиаторов

ппроект ОУТ с предлагаемыми секциями радиаторов без поправки на климатические условия

Рис. 2. Расчет годовых приведенных затрат на систему охлаждения

Как видно, затраты на изготовление и эксплуатацию охлаждающих устройств тепловозов с применением каплеобразных форм трубок в секциях радиаторов в значительной мере выгодней, чем применение стандартных радиаторов.

Опыт применения радиаторов с трубками увеличенного сечения до $40 \mathrm{mм}^{2}$ свидетельствует об их более высокой надежности, это дает основания предполагать, что разработанная секция будет также иметь более высокую техникоэкономическую эффективность.

В ходе процесса оптимизации проведен сравнительный расчет целевой функции для различных климатических условий эксплуатации. Сравнивая полученные данные, сделаем вывод, что 
Рухомий склад та спеціальна техніка залізничного транспорту. Локомотиви

стоимость жизненного цикла

охлаждающего устройства тепловоза при

проектировании значительно зависит от

режима работы тепловоза. Это

обстоятельство обусловлено меньшими затратами мощности на привод вентилятора холодильной камеры и как следствие снижением потребления топлива на вспомогательные нужды.

\section{Список использованных источников}

1. Беленький, А.Д. Диагностика системы охлаждения тепловозов [Текст] / А.Д. Беленький, В.П. Свиязев, В.А. Лаптев // Локомотив. - 1985. - №5. - С. 30-31.

2. Захарчук, А.С. Моделирование охлаждающего устройства дизелей [Текст] / А.С. Захарчук. - Деп. в ЦНИИТЭИ МПС 10.05.77, № 521/77. - Л.: Изд-во ЛИИЖТ, 1997. - 15 с.

3. Исаченко, В.П. Теплопередача [Текст] / В.П. Исаченко, В.А. Осипова, А.С.Сукомел. - 2-е изд. - М.: Энергия, 1969. - 440 с.

4. Куликов, Ю.А. Системы охлаждения силовых установок тепловозов [Текст] /Ю.А. Куликов. - М.: Машиностроение, 1988. - 280 с.

5. Новачук, Я.А. Проблемы модернизации тепловозов для работы в условиях низких температур [Текст] / Я.А. Новачук, А.Н. Тепляков, А.С. Слободенюк // тр. междунар. науч.практ. конф. «Модернизация тепловозов - пути решения». - Якутия, 2007. - С. 47-52.

6. Норенков, И.П. Введение в автоматизированное проектирование технических устройств и систем [Текст] / И.П. Норенков. - М.: Высшая школа, 1980. - 311 с.

Рецензент д-р техн. наук, профессор А.В. Устенко

Пасько Ольга Владимировна, канд. техн. наук, доцент эксплуатации и ремонта подвижного состава.

Белохонов Виктор Викторович, слухач ІППК, гр. МЗ-Л-Б-11.

Pasko O.V., cand. of tehn. sciences; Belohonov V.V. 